\title{
Entre Saberes, Identidades e Jogos de Poder na Reestruturação da Educação Escolar Indígena no Paraná
}

\section{Ana Caroline Goulart}

\section{RESUMO}

Refazer os sentidos e a organização da educação escolarizada tem sido uma intensa preocupação de profissionais indígenas que atuam nas escolas dentro de suas terras. Saberes e memórias que enfrentam tentativas históricas de controle e formatação nos colocam frente a um cenário de disputa e distribuição desigual de poder quando pensamos, por exemplo, na (re) formulação curricular e formação de professores. É a partir desse cenário, que se apresenta entre os povos indígenas no Paraná, que desenvolvo uma reflexão acerca das transformações identitárias, políticas e escolares, entendendo-os como indissociáveis. Concomitante a isso, proponho um olhar para as relações entre professores indígenas e não indígenas a partir de suas perspectivas sobre educação escolar, currículo e interculturalidade, ressaltando o caráter político que é atribuído às escolas indígenas e a protagonismo de profissionais indígenas na gestão das escolas e na progressiva substituição de professores não indígenas.

Palavras-chave: Educação indígena. Interculturalidade. Identidade.

\section{EDUCAÇÃO ESCOLAR INDÍGENA, CONFLITOS E PROJETOS}

Os projetos de escola e o protagonismo indígena têm indicado um novo cenário de enfrentamentos e descobertas: a Universidade. São diversas as experiências de políticas de acesso indígena ao ensino superior em todo o Brasil (BARROSOHOFMMAN \& LIMA, 2002). Uma delas é encontrada no Paraná - território habitado por Kaingang, Guarani e Xetá - onde foi criado o Vestibular dos Povos Indígenas, um processo de seleção diferenciado, que completa 14 anos em 2015.

As experiências que despontaram com essa nova possibilidade foi o tema ao qual me dediquei a pesquisar durante o mestrado em Antropologia Social pela Universidade Federal do Paraná, entre os anos de 2012 e 2014. Desde 2002 indígenas Kaingang e Guarani puderam acessar o ensino superior por meio de um processo seletivo específico direcionado às universidades estaduais. Inúmeras experiências foram sendo traçadas ao longo desses 13 anos e, assim, suscitando reflexões sobre os saberes

Mestre em Antropologia Social pela Universidade Federal do Paraná (UFPR); tutora na especialização em Educação das Relações Étnicoraciais - NEAB/ UFPR; professora de Sociologia no ensino médio em Curitiba. E-mail: carolgoulart2@ gmail.com 
construídos nas Universidades, bem como o projeto de escola e de educação pretendidos pelos Kaingang e Guarani.

Ao longo do trabalho de campo tive a oportunidade de estreitar minha relação com alguns universitários Kaingang e Guarani na Universidade Estadual de Londrina - instituição em que me graduei - e conhecer um pouco do percurso escolar que viveram nas escolas das Terras Indígenas, doravante identificadas por T.Is., e da cidade, a partir disso, foram se destacando as experiências relacionadas à percepção da autoimagem, que oscilava entre a imagem positiva e a negativa, mas com preponderância da segunda. Diversas foram as lembranças de violência sofrida e de um processo que D’Angelis (2008) denominou como “alienação da própria história”. As lembranças da infância escolar - que passa entre as décadas de 1970, 1980 e 1990 - em seus relatos os fizeram reviver experiências marcantes que podem ser percebidas como um período de construção negativa da própria identidade, estabelecida por um ensino e metodologias que obedeciam às regras de disciplinarização e distanciamento das noções de espaço e tempo particulares às crianças Guarani e Kaingang, que também viviam (e vivem) outros processos socializadores e educativos fora da escola. Nesse período citado, praticamente, não havia profissionais indígenas para atuarem nas escolas, entretanto, existiam algumas possibilidades de formação do que foi chamado de "monitores indígenas" e, ao longo dos anos, alterações políticas deram outro caráter à formação de profissionais para as escolas.

As construções legais direcionadas à educação escolar indígena e ao aumento da procura pela formação de professores indígenas aconteceram de forma paralela, destacando-se projetos de formação, que se diferenciam de acordo com o contexto político em que foram pensados. No que se refere à formação de professores Kaingang e guarani no estado do Paraná, indico quatro momentos cruciais que me foram ressaltados, tanto por alguns de meus interlocutores quanto por alguns professores bilíngues mais velhos. Considero como períodos de destaque os seguintes:

a) Internato Kaingang Clara Camarão, com seu auge na década de

b) 1970 ;

c) Projeto de Educação Reviver Indígena (PERI), com início em 1997, envolvendo os povos Kaingang, Guarani e Xokleng;

d) Criação de Magistérios Indígenas, sobretudo em 2004 e 2006;

e) Vestibular Indígena Diferenciado, a partir de $2001^{1}$. 
O primeiro momento pode ser considerado, entre os Kaingang, o dos tempos de formação profissional que recebiam na escola Indígena Clara Camarão, construída em 1970 na Terra Indígena Guarita, localizada no município de Tenente Portela - Rio Grande do Sul. Esse projeto de formação de profissionais indígenas contou com a parceria da FUNAI, Summer Institute of Linguistics (SIL) e Igreja Evangélica de Confissão Luterana no Brasil (IECLB), para sua construção. O período de funcionamento da escola foi marcado pela presença da missionária alemã Úrsula Wiesemann que, desde aproximadamente o início da década de 1950, através do SIL, começou a realizar alguns trabalhos linguísticos junto aos Kaingang ${ }^{2}$ (TOMMASINO, 2003; FAUSTINO, 2006; D’ANGELIS, 2008).

Na Escola Clara Camarão, cujo regime era de internato, conviviam os Kaingang de toda a região Sul, onde passavam cerca de quatro anos para completarem a formação oferecida de "monitores bilíngues" e então atuarem nas escolas das Terras Indígenas. Segundo o relato de Andila Inácio Belfort, Kaingang do Rio Grande do Sul e ex-aluna da escola Clara Camarão, todos ali tinham que trabalhar das seis da manhã às dez da noite, além de ser proibida a conversa entre eles enquanto estivessem sozinhos. Andila conta que por diversas vezes fizeram greve de fome e paralisaram as atividades por já estarem esgotados do rígido sistema de internato. Lembra-se também que frequentemente quebrava as regras de silêncio, recebendo castigos que duravam meses. Nos períodos de castigo, Andila permanecia na casa da diretora Úrsula Wiesemann, prestando serviços domésticos e auxiliando na tradução do Novo Testamento para o Kaingang (BELFORT, 2005). O projeto de formação de "monitores bilíngues" teve um período de aproximadamente dez anos, com suas atividades finalizadas na década de 1980.

O período antecedente à Constituição de 1988 (BRASIL, 1988) priorizou um projeto de educação que tinha por princípios básicos a transição linguística e cultural, cuja atuação indígena não ultrapassasse o status de "monitores", isto é, auxiliares dos professores não indígenas. Em seu artigo sobre a experiência na escola Clara Camarão, Andila Belfort expõe a insatisfação Kaingang diante das acusações de professores não indígenas durante uma reunião com a FUNAI de Brasília:

A reunião acabava de começar quando os professores "fóg” nos alvejaram com acusações infundadas como: que estaríamos fazendo as crianças perderem tempo alfabetizando-as em Kaingang, que não tínhamos escolaridade suficiente para exercer o magistério, sendo assim o projeto não tinha razão de ser, que tudo poderia ficar bem se os monitores só auxiliarem 
os professores “fóg” na limpeza, na merenda e no diálogo entre eles e as crianças. (BELFORT, p.14, 2005).

Toda a década de 1980, como já mencionado por Fernandes (2003), foi marcada pela organização política de diversos grupos indígenas em torno da educação escolar e formação de professores indígenas. Com a Constituição no final da década de 1980, um novo momento político se colocou aos povos indígenas residentes no estado do Paraná, considerando que, em 1991, como já mencionado, o MEC se tornou o novo agente na educação escolar indígena no território nacional.

Entre a intervenção religiosa e a estatal, Faustino (2006) chama a atenção para o que identificou como "ação alternativa" na educação indígena, isto é, uma ação desenvolvida fora do âmbito estatal e fora dos princípios religiosos de conversão. Menciona, como exemplo, a “Associação Projeto Educação do Assalariado Rural Temporário" (APEART), ONG constituída pela Comissão Pastoral da Terra (CPT) em 1992, que teve por objetivo principal alfabetizar uma população rural, como boias frias. Em 1997 a APEART, sob a assessoria da antropóloga Kimiye Tommasino, criou o Projeto Educação Reviver Indígena - (PERI) direcionado aos Kaingang, Guarani e Xokleng em doze Terras Indígenas no estado (AMARAL, 1998).

A APEARTE, com o PERI, pode ser considerado o segundo momento de maior destaque entre os povos indígenas no estado, não apenas na formação escolar, mas também na formação de novos professores indígenas, pois aqueles que passaram pelo PERI foram ocupando os espaços das escolas, ao darem continuidade na formação educacional nos cursos de magistério indígena realizados no estado.

A fim de incluir em suas pautas o tema da diversidade educacional, foi criado, em 2003, no Paraná - dentro da SEED - o Departamento de Diversidade (DEDI), composto pela "alfabetização de jovens, adultos e idosos, a educação escolar indígena, a educação do campo, a educação das relações étnico-raciais e afrodescendência, e de gênero e diversidade sexual" (AMARAL, 2010).

No que se refere às atribuições da coordenação da educação escolar indígena, esta é:

responsável pela condução da política de educação escolar indígena no Paraná, voltada às diretrizes, ao diagnóstico e à organização das escolas indígenas (estadualizadas a partir do ano de 2008), à formação inicial e continuada dos professores Kaingang, Guarani e Xetá do estado, à produção de materiais de apoio pedagógico, à implementação dos conteúdos relacionados à História e Cultura Indígena (Lei Federal n. 11.645/08) no currículo da educação básica, dentre outras ações fundamentais para uma educação escolar intercultural, bilíngue, específica 
e diferenciada, como preconiza a legislação brasileira (AMARAL, 2010 p.10).

Foi somente em 2006, no governo de Roberto Requião (PMDB), que o Paraná deu início ao "Curso de Formação de Docentes Indígenas Bilíngues para a Educação Infantil e Anos Iniciais do Ensino Fundamental, em Nível Médio, na Modalidade Normal - Aproveitamento de Estudos" (PARANÁ, p. 24, 2006), sediado na época em Faxinal do Céu. Com uma duração de cinco anos, o curso foi concluído no final de 2012 por 66 professores Kaingang e Guarani de 16 terras indígenas no estado.

Outra ação que alcançou os indígenas no Paraná foi o "Programa de Formação para a Educação Escolar Guarani na Região Sul e Sudeste do Brasil KuaaMbo'o - ConhecerEnsinar", conhecido como "Protocolo Guarani". O Protocolo aconteceu em parceria firmada entre o MEC através da SECAD, FUNAI e secretarias de educação dos estados de Santa Catarina, Paraná, São Paulo, Rio Grande do Sul, Espírito Santo e Rio de Janeiro, em 2004, cuja duração foi de cinco anos. Nesse magistério específico havia a possibilidade de iniciar o Curso em Santa Catarina e realizar atividades no estado de origem do cursista e mesmo em sua Terra Indígena (BRASIL, 2007).

Tanto o Protocolo Guarani quanto o Curso de Docentes Bilíngues marcam um terceiro momento na formação de professores indígenas. Em diálogo com as primeiras mudanças apresentadas por Fernandes (2003) nas décadas de 1970 e 1980 no interior dos movimentos indígenas e indigenistas, esse período de transformações em nível nacional e estadual tem a presença indígena como fundamental. Essa presença se manifesta na importância da ocupação de cargos nas escolas, propiciada inicialmente pelo magistério, um significativo momento de fortalecimento do protagonismo indígena na educação escolar.

Outra possibilidade de formação de professores no Paraná surgiu com o ingresso de Kaingang e Guarani nas universidades estaduais. Desde 2002 vive-se nesse estado a experiência de formação em cursos regulares através de vagas suplementares com a Lei 13.134, ampliando assim a atuação indígena como professores e alcançando inclusive a gestão das escolas.

Os quatro momentos de maior destaque brevemente mencionados indicam as mudanças na percepção sobre a atuação indígena nas escolas, ressaltando que os projetos de formação de professores estiveram ligados, de alguma maneira, ao projeto de escola desejado, seja pelas instâncias indigenistas, ou pelos anseios indígenas. Enquanto o período de integração e civilização, com a pedagogia do bilinguismo de transição, reservava ao "monitor bilíngue" apenas funções secundárias em salas de aula 
- como auxiliares de professores não indígenas - o período pós Constituição de 1988 apresentou significativas reflexões sobre o papel e a representação indígena em sala de aula, tendo seus direitos garantidos como profissional reconhecido.

Ainda em passos de construção de um novo projeto de ação escolar, permanece a precariedade na formação oferecida aos professores indígenas e não indígenas sobre histórias, culturas e particularidades dos povos indígenas. Sobre isso, D’Angelis faz a seguinte análise:

\begin{abstract}
A segunda consequência concretiza-se no que temos chamado, em outros trabalhos, de folclorização da cultura indígena, e na adaptação da escola tradicional ao contexto indígena, pela incorporação, ao currículo escolar, de elementos culturais folclorizados. Seu valor identitário e cultural é tanto quanto o do cocar de penas de galinha colocado nas cabeças das crianças (não-índias, ou indígenas mesmo) no famigerado "Dia do Índio" (19de Abril). A consequência ou seja, o resultado nefasto desse tipo de concepção e prática educacional (que uns chamam de boca cheia, "intercultural" ou "bicultural") é a alienação da criança e do jovem indígena em relação às suas próprias raízes culturais. (D’ANGELIS, 2008, p. 11).
\end{abstract}

Embora residam Kaingang, Guarani e Xetá, onde hoje é o território paranaense, as escolas indígenas são Kaingang e Guarani ${ }^{3}$. Em 2010 a SEED/DEDI juntamente aos Xetá, ao NRE de Cornélio Procópio, a Universidade Estadual de Maringá ${ }^{4}$, ao Museu Paranaense, a Universidade de Brasília ${ }^{5}$ e ao Instituto do Patrimônio Histórico e Artístico Nacional (IPHAN) reuniram-se na cidade de São Jerônimo da Serra para a elaboração da Oficina de Produção de Material Xetá. No início de 2013 os livros foram finalizados e distribuídos para as escolas do Paraná.

Entre as escolas Kaingang e guarani há uma diferença primeira: o ensino da língua indígena. Nas escolas Kaingang o fortalecimento do ensino da língua em sala de aula é o aspecto central em sua política educacional. Nas escolas guarani, e no caso da escola Cacique Kofej, na Terra Indígena São Jerônimo, onde frequentam alunos de três etnias, o ensino da língua indígena ocorre apenas em traduções de músicas infantis do português para o Kaingang ou guarani, trabalhando-se com a alfabetização, mas não com o letramento. Deste modo, nessa T.I. grande parte das crianças não conversam em guarani e Kaingang. Ainda que sejam alfabetizadas, não há o sentido social do uso da linguagem.

No segundo semestre de 2013 iniciei a participação, como bolsista recémformada, no projeto "Escola e seu currículo: lugar de pertença e identidade", coordenado por três professores de diferentes áreas da Universidade Estadual de

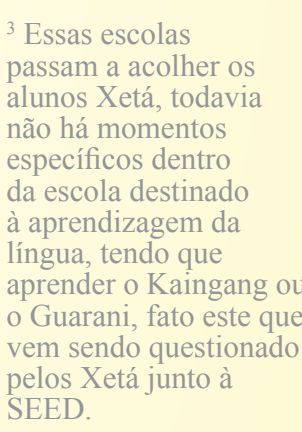

SEED

${ }^{4}$ Participação de professores integrantes do Laboratório de Arqueologia, Etnologia e Etno-História, que desenvolvem pesquisas de extensão nas terras indígenas no Paraná, com forte ênfase na educação.

${ }^{5}$ Participaram os linguistas Aryon Dall'lgna Rodrigues e Ana Suelly, que já vêm trabalhando há algum tempo com o estudo da língua xetá. 
Londrina. O objetivo principal do projeto era a realização de um diagnóstico sobre a situação vivenciada pelos profissionais nas escolas indígenas, preocupando-se com detalhes, como a estrutura física, a formação de professores e a construção de um currículo nas escolas da região norte do Paraná.

Essa participação me possibilitou uma aproximação com as escolas e os agentes indígenas da região norte do Paraná, dentre eles, gestores, professores e auxiliares educativos. Foram divididas duas equipes para a realização do trabalho de campo, uma equipe responsável pelas pesquisas em terras guarani e outra em terras Kaingang, cada uma acompanhada por um recém-formado e eventualmente por algum professor coordenador. Durante o trabalho de campo acompanhei as pesquisas nas terras Kaingang - São Jerônimo, Apucaraninha e Barão de Antonina - com um total de sete escolas indígenas nessas T.Is.

Todavia, meu primeiro contato com as escolas Kaingang ocorreu em anos anteriores - 2009, 2010 e 2011 - através das divulgações dos Vestibulares feitas junto aos professores da CUIA, quando ainda participava do Programa de Formação Intercultural $^{6}$.

Em abril de 2013 retornei para a T.I Apucaraninha, antes de me vincular ao projeto de extensão. O objetivo principal dessa minha visita era conversar com meus interlocutores Kaingang que, além de universitários, mantinham algum vínculo com as escolas. Nesse momento de campo, voltado para a pesquisa da dissertação, conheci apenas a escolas da Sede:

João Kavagtan, que oferece anos iniciais, e a escola Benedito Rokag, com ensino fundamental e médio. Em viagens seguintes como bolsista do projeto de extensão conheci as áreas Barreiro, Serrinha e Água Branca.

Algumas das T.Is, nas quais vivem meus interlocutores Kaingang e Guarani, têm escolas somente até a $4^{\mathrm{a}}$ série $^{7}$, com professores indígenas bilíngues e professores não indígenas que, em sua maioria, têm contratos temporários pelo Processo Seletivo Simplificado realizado pelo governo do Paraná em diferentes épocas do ano ${ }^{8}$. A oferta do ensino médio na região norte do Paraná foi garantida nas T.Is Apucaraninha e São Jerônimo. Ambas tiveram as obras precariamente finalizadas no início de 2013 e, embora não tenham sido inauguradas, foram postas em funcionamento.

As duas escolas tiveram um início de ano letivo com diversas complicações. A diretora não indígena da escola Cacique Kofej, na T.I. São Jerônimo, caciques e 
lideranças reuniram esforços para que conseguissem água encanada na escola, pois foi entregue sem essa estrutura.

Já a escola Benedito Rokag9, na T.I. Apucaraninha, passou por constantes dificuldades, desde a locomoção dos professores até a ausência de merenda. Quando visitei a escola no início de abril de 2013 a biblioteca ainda não funcionava devido à falta de livros, e estes só chegaram à escola após seis meses, mediante o empenho de alguns professores em fazer uma campanha de doação. O laboratório de informática também não estava pronto, os computadores já haviam chegado, mas não era possível instalá-los pela falta de outros equipamentos. Até o final do primeiro semestre não foram entregues extintores e a merenda não condizia com o que, na mesma época, estava sendo veiculado no site do governo.

Após aproximadamente dois meses sem receber a merenda ${ }^{10}$, caciques, equipe pedagógica e professores fizeram a solicitação de merenda ao Núcleo Regional de Ensino (NRE) de Londrina, sem obter retorno. Quando foram feitas denúncias aos telejornais, a merenda foi entregue no dia seguinte. Contudo, mesmo após a entrega, os problemas persistiram, pois os professores encontraram carnes e outros produtos com a data de validade ultrapassada. A saga da alimentação na escola Kaingang não foi totalmente resolvida, pois, segundo os professores, a maior parte da merenda ainda tem sido repassada pela "escola de baixo", maneira a que se referem à escola de anos iniciais João Kavagtan.

Toda a estrutura das escolas que têm sido construídas segue o mesmo padrão. Em formato circular, essas escolas possuem, além das salas de aula, um espaço externo com quadro, mesas e cadeiras de concreto, utilizado em dias de muito frio, quando os alunos preferem ficar ao sol, e usado também para jogos de xadrez. As escolas ainda não possuem quadra para aulas de Educação Física. Neste caso, os professores da T.I Apucaraninha fazem algumas atividades no campo de futebol da aldeia, já em São Jerônimo utilizam o ginásio da cidade para algumas atividades ${ }^{11}$.

Um aspecto muito presente nas escolas indígenas é a improvisação de espaços de acordo com as necessidades da equipe, como acontece na escola Cacique Onofre Kanhgren na T.I Barão de Antonina. Criada em 1984, a escola era um prédio com algumas salas de aula, compartilhando o espaço com a cozinha, com a sala de reuniões, a secretaria e a diretoria. Conforme o Projeto Político Pedagógico, a estrutura inicial da escola definia-se da seguinte maneira:

A professora Marlene do Carmo Veloso atuou nessa escola no ano de 1988, ela relatou que quando chegou ao Barão o que presenciou foi um verdadeiro
Nas aldeias em que os alunos precisam ir para a cidade o deslocamento é feito normalmente por ônibus do município ou carros próprios.

${ }^{8}$ Faustino (2006) fala sobre o interesse de integrantes do SIL nesse processo seletivo para permanecerem dentro das escolas indígenas, porém, durante meu período de campo não tive conhecimento se entre os professores havia alguém do SIL.

${ }^{9}$ A Escola tem à frente uma diretora Kaingang e dois professores indígenas, um Kaingang e outro Xokleng - este último é casado com uma Kaingang da aldeia, ministra aulas de Português e também é aluno da Licenciatura Intercultural Indígena do Sul da Mata Atlântica, realizada na Universidade Federal de Santa Catarina. Os demais professores são, em sua maioria, de Londrina e temporários que entraram pelo Processo Seletivo Simplificado - PSS Esses professores deslocam-se diariamente ou passam a noite dormindo na escola durante os dias de aula. Em épocas de chuva o acesso à aldeia se torna mais difícil, pois vários bolsões de água se formam em algumas partes da estrada de terra. Entretanto, o que mais dificulta a viagem é a falta de um transporte que consiga enfrentar estradas enlameadas em dias de chuva. 
abandono. Na parte da educação não existia nada a escola era um depósito de algodão, os mobiliários estavam jogados pelos cantos. A documentação estava um pouco na escola, um pouco na enfermaria, na sede do posto, nas casas dos indígenas, existem documentos que até hoje não foram encontrados. $^{12}$

Em 2009 foi construída uma nova unidade para o posto de saúde, e a antiga foi doada para a escola. Nesse prédio foram organizados espaços de diretoria, sala dos professores, biblioteca, um "laboratório" improvisado com três computadores, mas apenas um é mais utilizado para o acesso a internet. Nos fundos do pequeno prédio doado fica a cozinha e, ao lado, uma reduzida sala de aula, mas que recebe apenas dois alunos.

É preciso ir além das questões estruturais da escola para compreender um pouco mais de perto como tem se construído o cotidiano escolar e os discursos em torno da formação escolar indígena. Com relação a isso, dois professores Kaingang da T.I. Apucaraninha e uma professora não indígena me disseram que o ensino na escola indígena ainda tem sido atropelado por um ensino de "escola da cidade", ressaltando as percepções de espaço e ensino ainda de modos muito limitadores. Diferente das outras escolas, os alunos da T.I Apucaraninha conversam em sua língua materna que, nesse caso, é o Kaingang, tanto na "escola de baixo" quanto na "escola de cima", bem como em qualquer espaço da aldeia, independente da presença de não indígenas.

Enquanto estive na T.I Apucaraninha, alguns professores não indígenas demonstraram grande incômodo com o fato de os alunos não permanecerem nas salas de aula e, por diversas vezes, notei que saiam procurando os alunos pelo pátio da escola. Certa vez, conversando com o professor (não indígena) de geografia sobre sua experiência em sala de aula, ele me contou sobre os anos que trabalhou na escola da cidade de Tamarana - onde se recebe alunos Kaingang ${ }^{13}$ - recordando que lá eles também saiam da sala e não retornavam. Segundo disse, nesse tempo ficavam caminhando pelo pátio ou saiam da escola para passear pela cidade ${ }^{14}$.

Aqueles que precisam deslocar-se até a cidade para concluir a formação escolar fazem no $6^{\circ}$ ano, frequentando escolas onde por muito tempo foram proibidos de falar a língua Kaingang e Guarani, vivenciando também outras situações de rejeição. Na T.I Ivy Porã, em Abatiá, os professores Guarani insistem para que todos tentem conversar na língua de seu povo, incentivando seu ensino na escola da aldeia, apesar de poucos serem falantes do idioma.

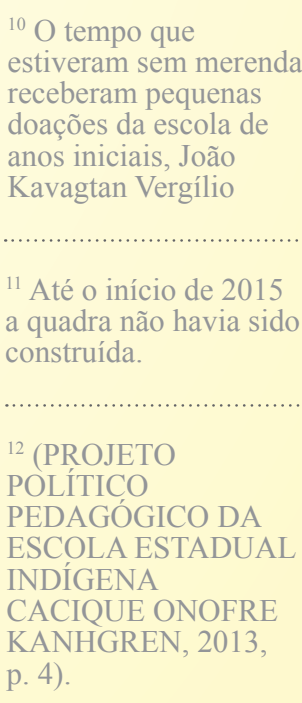

p. 4) 
Quando iniciaram a ocupação dessa área - Ivy Porã - passaram pela dificuldade na formalização da educação escolar, pelo caráter de ocupação que ainda havia e do conflito gerado. Desse modo, os alunos foram encaminhados para as escolas rurais mais próximas. O conflito instalado na aldeia dificultou a ida desses alunos para as escolas, pois fazendeiros da região tentavam impedir as matrículas e os demais alunos não indígenas chegaram a agredir fisicamente os Guarani, que, para frequentarem as aulas na cidade, necessitaram do acompanhamento da Polícia Federal (ASSIS, 2011).

Todavia, o ensino médio na aldeia tem causado discordâncias entre os professores indígenas já que, de um lado, a possibilidade de concluir os estudos na T.I é encarada de extrema importância, tanto pelo seu sentido político de afirmação identitária quanto pela segurança em estar distante dos perigos da cidade e, por outro lado, o afastamento do ensino urbano tem causado certa preocupação entre familiares e professores, que veem no ensino da cidade a oportunidade de ter um melhor aprendizado do português. Na percepção de alguns, o ensino na cidade propicia uma interação ampliada com os não indígenas, interação essa considerada essencial por parte de alguns Kaingang e Guarani, que vislumbram a vida universitária como um projeto de futuro para si ou para seus filhos.

No período de visitas às aldeias com a equipe do projeto de extensão, um dos questionamentos feito pelos professores indígenas, e também por algumas pessoas mais velhas que encontramos, foi com relação à massiva presença de professores não indígenas em salas de aula, reiterando a todo o momento que, para o professor trabalhar na escola indígena, é preciso "ter cabeça de índio". Até o final de 2013 a gestão das escolas indígenas seguiu com três diretores indígenas e quatro pedagogas indígenas. Entretanto, ainda que se tenha um aumento na presença de profissionais Kaingang e Guarani, é possível identificar a desigual presença em sala de aula, cuja preponderância é não indígena.

Em conversas com professores não indígenas, a retórica do ensino e da escola diferenciados despontava como o ponto peculiar e atraente das escolas. Ainda que afirmassem com segurança sobre a dessemelhança entre escolas indígenas e outras escolas, era possível perceber a imprecisão de tal afirmativa quando perguntávamos qual seria então a diferença entre a escola Kaingang e a escola do campo. Com recorrência nos era argumentado: "aqui a tradição é diferente", " a cultura é diferente". Conceitos utilizados - cultura e tradição - para falar sobre uma "escola diferenciada" eram relacionados apenas à pronúncia e às aulas de Kaingang, bem como ao uso do
A escola de Tamarana continua recebendo alunos Kaingang, porque, mesmo com a criação da escola com ensino fundamental e médio na aldeia, alguns pais preferem mandar seus filhos para a escola da cidade, onde acreditam ter um ensino de melhor qualidade.

${ }^{14}$ Esse tem sido um dos elementos de grande preocupação por parte da comunidade e dos professores indígenas, pois, na cidade, eles se deparam com os benefícios (escola) e com os "males" que são as drogas, já que muitos dos alunos iam para bares ou espaços distantes dos olhares da população, o que vem a ser resolvido - para alguns - com a criação do ensino fundamental e médio na aldeia. 
espaço escolar pelos alunos que acontece de forma mais livre e dinâmica do que em escolas da cidade.

A metodologia, a organização curricular e a avaliação não indicam propostas opostas às encontradas em escolas urbanas, reduzindo, então, o "diferente" à apropriação do espaço escolar feita pelos alunos. O que evita, portanto, uma maior problematização de propostas que reorganizem as metodologias e organização curricular e espacial do ambiente escolar.

Desse modo, currículo e espaço escolar parecem indicar caminhos de reflexão sobre o modelo de educação e escola oferecido tanto em áreas indígenas quanto nas cidades que contam com a presença indígena nas salas de aula. A “disciplinarização das crianças" no período militar, a qual se referiu Tommasino (2003), ainda é encontrada principalmente nas escolas urbanas, que partem do princípio do controle. Essa realidade distancia-se do modo como Meliá (1979) concebe a educação, que em suas palavras trata-se de um "sistema total", levando em consideração o uso do espaço em suas múltiplas possibilidades, não apenas sentados em cadeiras como meros receptores de saber.

Segundo o que me contou a diretora Kaingang da escola Benedito Rokag, o programa curricular aplicado nas escolas indígenas do Paraná não passa por nenhuma alteração em sua estrutura e as solicitações de mudança encaminhadas ao NRE não são discutidas. Toda a organização escolar indígena segue o mesmo modelo das escolas urbanas, o que dificulta a construção de sentido do conhecimento transmitido. Antonella Tassinari concebe a escola indígena como "espaços de fronteiras, entendidos como espaços de trânsitos, articulação e trocas de conhecimentos, assim como espaços de incompreensões e redefinições identitárias" (TASSINARI, 2001, p.50). Nesse sentido, as incompreensões por parte do Núcleo de Ensino, em transformar o espaço escolar indígena a partir de outros parâmetros que não os aplicados em escolas urbanas, apresentam se como elemento central nesse espaço de fronteira, pois acaba imobilizando propostas de educação diferenciada. Desse modo, o diálogo inter-étnico e a troca de conhecimentos no espaço de fronteira parece não ocorrer de forma efetiva nas escolas indígenas no Paraná.

Talvez seja possível dizer que a interculturalidade existente nas escolas indígenas, propiciada pelas relações entre professores não indígenas e professores e alunos Kaingang, esteja próxima do que Walsh (2009) descreve como uma interculturalidade funcional. Ou seja, há a permanência de uma perspectiva sobre 
educação escolar indígena - a ideia de uma diferença que não se sabe ao certo o que é - que limita a reflexão sobre as relações de desigualdade e poder existentes na escola e no currículo.

Nota-se essa situação, por exemplo, quando nos damos conta de que a legislação referente à educação escolar indígena, que determina a autonomia de propostas pedagógicas e a reorganização curricular, tem sido atravancada por uma noção homogênea e hegemônica de educação e escola, tanto por parte de alguns professores quanto por parte de agentes estatais.

Entretanto, essa interculturalidade funcional percebida em escolas indígenas no norte do Paraná, por meio de discursos e ações (ou não ações) vai sendo transformada - há algum tempo e cada vez mais - pela intencionalidade e agência de outros sujeitos, como os professores Kaingang e alguns professores não indígenas que, com frequentes reflexões, buscam uma completa transição a uma interculturalidade crítica, que considere a estrutura de desigualdade e poder no sistema educacional e, a partir disso, trace caminhos possíveis de ações "descolonizadoras” das escolas.

\section{CONSIDERAÇÕES FINAIS}

Embora a pesquisa tenha sido finalizada, o que apresento neste artigo não são ideias acabadas, pois as transformações na educação escolar indígena têm sido constantes. Desse modo, enfatizo a importância no olhar para as perspectivas de quem atua nessa modalidade de educação escolar, entendendo-a como necessária para que não caiamos no risco de uma interculturalidade funcional, visto que apenas a retórica do "diferente" não é suficiente para uma transformação educativa e escolar. Não sem surpresa, pode ser uma potencial armadilha, já que a diversidade étnica é legitimada legalmente e no discurso, mas nem sempre é contemplada de fato em ações e situações de diálogo e negociações entre os diferentes agentes.

\section{REFERÊNCIAS}

AMARAL, Wagner Roberto. A ousadia do Serviço Social no Espaço das ONG'S. Serviço Social em Revista. Volume 1 - Número 1 Jul/Dez 1998. 
As trajetórias dos estudantes indígenas nas universidades

estaduais do Paraná: sujeitos e pertencimentos. Tese (Doutorado em Educação) Universidade Federal do Paraná. Curitiba, 2010

ASSIS, Valéria. Mito e História nas Narrativas dos Guaranis da Bacia do

Paranapanema. Tese (Doutorado em Antropologia Social). Universidade Federal de Santa Catarina, Florianópolis, 2011.

BARROSO-HOFFMANN, Maria; SOUZA LIMA, Antonio C. (orgs.).

Etnodesenvolvimento e políticas públicas; Estado e povos indígenas; e Além da tutela: bases para uma nova política indigenista. Rio de Janeiro: Contra Capa Livraria, 2004.

BELFORT, A. I. A formação dos primeiros professores indígenas no Sul do Brasil. Cadernos de Educação Escolar Indígena - $3^{\circ}$ Grau Indígena, Barra do Bugres,

UNEMAT, Cáceres, v. 4, n. 1, p. 9-20, 2005.

BRASIL. Ministério da Educação. Educação escolar indígena: diversidade sociocultural indígena ressignificando a escola. Cadernos SECAD 3, Brasília, 2007.

D'ANGELIS, Wilmar da Rocha. Educação escolar e ameaça à sobrevivência das línguas indígenas no Brasil Meridional. BRASA IX - New Orleans/LO, USA, 27-29 mar 2008.

FAUSTINO, R. C. Política educacional nos anos de 1990: o multiculturalismo e a interculturalidade na educação escolar indígena. Tese (Doutorado em Educação) - Universidade Federal de Santa Catarina, Florianópolis, 2006.

FERNANDES, Ricardo Cid. Política e Parentesco entre os kaingang: uma análise etnológica. Tese (Doutorado em Antropologia Social) - Universidade de São Paulo. São Paulo, 2003

MELIÀ, B. Educação indígena e alfabetização. São Paulo: Loyola, 1979. (Coleção "Missão Aberta").

PARANÁ. Educação Escolar Indígena. Secretaria de Estado da Educação.

Superintendência de Educação. Departamento de Ensino Fundamental.

Coordenação da Educação Escolar Indígena. - Curitiba : SEED - Pr, 2006.

SILVA, Carmen Lúcia da. Sobreviventes do extermínio: uma etnografia das narrativas e lembranças da sociedade Xetá. Florianópolis: UFSC, 1998.

(Dissertação de Mestrado em Antropologia Social).

TASSINARI, Antonella M. E. Escola indígena: novos horizontes teóricos, novas fronteiras de educação. In: SILVA, Aracy L.; FERREIRA, Mariana K.L.

Antropologia, história e educação: a questão indígena e a escola. São Paulo: Global, 2001.

TOMMASINO, Kimiye. Educação escolar indígena no Paraná. Revista Mediações. Londrina, vol.8, n.1, p.71-98, jan/jun. 2003.

WALSH, Catherine. Interculturalidade crítica e pedagogia decolonial: in-surgir, reexistir e re-viver. In: CANDAU, Vera Lúcia (org.). Educação intercultural na América Latina: entre concepções, tensões e propostas. 2009. 